\title{
AVALIAÇÃO DA VIABILIDADE DE SEMENTES DE AVEIA BRANCA PELO TESTE DE TETRAZÓLIO ${ }^{1}$
}

\author{
CAMILA RIBEIRO DE SOUZA², OSVALDO DE CASTRO OHLSON ${ }^{3}$, MARISTELA PANOBIANCO ${ }^{4}$
}

\begin{abstract}
RESUMO - A semente de aveia branca apresenta dormência quando recém colhida, sendo normalmente superada após um período de armazenamento, o que torna o teste de germinação algumas vezes ineficaz para avaliação da sua viabilidade. $\mathrm{O}$ objetivo neste trabalho foi estudar diferentes metodologias para a condução do teste de tetrazólio em sementes de aveia branca, visando estimar rapidamente a sua viabilidade. Foram utilizados cinco lotes de sementes de aveia branca, das cultivares Louise e IAC-7, testando-se os seguintes procedimentos: a) hidratação entre folha de papel toalha umedecida e embebição direta em água a $20^{\circ} \mathrm{C}$, por $18 \mathrm{~h}$; b) coloração por $2 \mathrm{~h}$, sobre papel e imersão direta na solução; c) concentrações de solução de tetrazólio a $0,1 \%, 0,5 \%$ e 1,0\%. Paralelamente, foram estudados dois tipos de preparo: corte longitudinal da semente através do embrião, com descarte de uma das metades e imersão da outra na solução de tetrazólio, a $30^{\circ} \mathrm{C}$, e corte com colocação das duas metades sobre papel filtro umedecido com a solução de tetrazólio, a $40{ }^{\circ} \mathrm{C}$. Com base nos resultados obtidos, concluiu-se que o teste de tetrazólio é promissor para avaliação rápida da viabilidade de sementes de aveia branca, com hidratação entre papel ( $18 \mathrm{~h}$ a 20 $\left.{ }^{\circ} \mathrm{C}\right)$, coloração sobre papel $\left(2 \mathrm{~h}\right.$, a $\left.40{ }^{\circ} \mathrm{C}\right)$ umedecido com solução de tetrazólio a 1,0\%;
\end{abstract}

Termos para indexação: Avena sativa, germinação, qualidade fisiológica.

\section{EVALUATION OF WHITE-OAT SEED VIABILITY BY THE TETRAZOLIUM TEST}

\begin{abstract}
White-oat seed shows dormancy when recently harvested, but this is normally overcome after storage, which sometimes makes the germination test for evaluating their viability unreliable. The objective of this study was to evaluate different methodologies for performing the tetrazolium test with white-oat seeds, to rapidly determine their viability. Five white-oat seed lots of "Louise" and "IAC-7" cultivars were used to test the following procedures for the tetrazolium assay: a) hydration between moistened paper towels and in soaked water at $20^{\circ} \mathrm{C}$, for $18 \mathrm{~h}$; b) coloring for $2 \mathrm{~h}$, on paper moistened with reagent and direct immersion in the reagent; c) tetrazolium solutions of $0.1 \%, 0.5 \%$ and $1.0 \%$. There were two types of seed preparation: seeds were cut longitudinally through the embryo, and one half was immersed in tetrazolium solution at $30^{\circ} \mathrm{C}$ or both halves were placed on filter paper moistened with tetrazolium solution, at $40^{\circ} \mathrm{C}$. Results showed that the tetrazolium test is promising for the rapid determination of seed viability, with hydration between paper $\left(18 \mathrm{~h}\right.$, at $\left.20^{\circ} \mathrm{C}\right)$, and by the coloring on moistened paper $\left(2 \mathrm{~h}\right.$, at $\left.40^{\circ} \mathrm{C}\right)$ with $1 \%$ tetrazolium solution.
\end{abstract}

Index terms: Avena sativa, germination, physiological quality

\footnotetext{
${ }^{1}$ Submetido em 17/08/2009. Aceito para publicação em 30/06/2010.

${ }^{2}$ Acadêmica do curso de Engenharia Agronômica, UFPR, bolsista de iniciação científica da UFPR/TN, e-mail: camilaribeiro@ufpr.br.
}

${ }^{3}$ Eng. Agr., M.Sc., Responsável Técnico do Laboratório de Análise de Sementes Oficial da Empresa Paranaense de Classificação de Produtos
(CLASPAR), Rua João Américo de Oliveira, 330, 80035-060, CuritibaPR, e-mail: osvaldodecastro@claspar.pr.gov.br.

${ }^{4}$ Professora Adjunto, Departamento de Fitotecnia e Fitossanitarismo, UFPR, Rua dos Funcionários, 1540, 80035-050, Curitiba-PR, e-mail: maristela@ufpr.br 


\section{INTRODUÇÃO}

A aveia branca (Avena sativa L.) é uma das mais antigas espécies cultivadas pelo homem, tendo como principal uso a alimentação humana e animal, pois produz alimentos com alta qualidade, ricos em fibras, vitaminas e minerais. Destaca-se também para pasto de inverno, produção de feno e silagem (CBPA, 1999), bem como para adubo verde (Calegari et al., 1996) e cobertura morta no plantio direto (Almeida, 1998).

O sucesso no estabelecimento de novas áreas com a espécie depende de satisfatória produção de sementes. A avaliação do potencial fisiológico da semente é um componente essencial nos programas de controle de qualidade adotados por empresas, pois quando efetuada corretamente permite a identificação de lotes com maior probabilidade de apresentar desempenho adequado no campo, fornecendo o retorno esperado.

Entretanto, são escassas as informações presentes na literatura sobre o controle de qualidade no processo de produção de sementes de aveia branca. A avaliação do potencial fisiológico das suas sementes apresenta dificuldade, em razão da falta de métodos consistentes (Garcia e Menezes, 1999; Borsato et al., 2000).

Dentre as determinações realizadas para verificação da qualidade fisiológica da semente está o teste padrão de germinação, no qual para aveia branca recomenda-se o período de cinco a 10 dias de condução (Brasil, 1992). Por outro lado, Delatorre e Souza (1998) constataram acréscimo progressivo do poder germinativo de aveia branca com o aumento da idade pós-colheita das sementes, provavelmente relacionado à dormência, o que ressalta a necessidade do desenvolvimento de testes que estimem rapidamente a viabilidade.

$\mathrm{O}$ interesse no estabelecimento de métodos rápidos para avaliar a viabilidade da semente, principalmente na compra e no manuseio durante o beneficiamento e armazenamento, levou ao desenvolvimento do teste de tetrazólio. Uma análise cuidadosa permite distinguir diferentes categorias de sementes viáveis e não viáveis (ISTA, 2003), além de possibilitar o diagnóstico dos principais problemas que podem afetar a qualidade da semente.

Na realização desse teste são indicados determinados procedimentos, tais como: a) pré-condicionamento, que visa ativar o metabolismo enzimático, facilitar o preparo das sementes e o desenvolvimento da coloração durante o contato com a solução de tetrazólio; b) seccionamento das sementes antes de serem submetidas à coloração, necessário para algumas espécies; c) coloração, variandose a concentração da solução de tetrazólio, o tempo e a temperatura de condicionamento; d) avaliação (Vieira e Von Pinho, 1999; Marcos Filho, 2005; Oliveira et al., 2005).

A International Seed Testing Association(ISTA, 2007) recomendou para aveia branca a hidratação das sementes durante 18 horas, a $20^{\circ} \mathrm{C}$, entre papel ou por imersão em água, desenvolvendo-se a coloração por duas horas, a $30{ }^{\circ} \mathrm{C}$, em solução de cloreto de tetrazólio a $1,0 \%$; com relação ao corte das sementes, foram recomendados o corte longitudinal (por meio do embrião e $3 / 4$ do endosperma) e o corte transversal. Por outro lado, as recomendações das Regras para Análise de Sementes (Brasil, 1992) diferem no tempo de hidratação, de seis para imersão em água e 18 horas entre papel, e na concentração da solução de tetrazólio $(0,1 \%$ e $0,5 \%)$.

Em razão da importância da espécie e da discrepância de informações para a condução do teste de tetrazólio em aveia branca, o presente trabalho objetivou determinar um protocolo eficiente para o teste, visando a avaliação rápida da viabilidade das sementes.

\section{MATERIAL E MÉTODOS}

A pesquisa foi conduzida no Laboratório de Análise de Sementes Oficial da Empresa Paranaense de Classificação de Produtos - CLASPAR, em Curitiba-PR, no período de janeiro a fevereiro de 2009.

Foram utilizados cinco lotes de sementes de aveia branca, dois da cultivar Louise e três da cultivar IAC-7, provenientes da safra 2007/07. As sementes não apresentavam dormência, uma vez que os testes foram realizados um ano após a colheita. Durante o período experimental, as sementes permaneceram armazenadas em sacos de papel Kraft, sob ambiente controlado $\left(14{ }^{\circ} \mathrm{C}\right.$ e $50 \%$ de umidade relativa do ar).

Inicialmente, foi realizada a determinação do grau de umidade e da germinação das sementes de cada lote. A determinação do grau de umidade foi realizada pelo método de estufa a $105 \pm 3{ }^{\circ} \mathrm{C}$, durante $24 \mathrm{~h}$, com duas subamostras de 5,0 g por lote, de acordo com as recomendações das Regras para Análise de Sementes (Brasil, 1992). Na condução do teste de germinação foram utilizadas quatro subamostras de 100 sementes por tratamento, distribuído sobre papel toalha, umedecido com água em quantidade equivalente a duas vezes a massa do substrato, formados 
rolos e colocados em germinador a $20{ }^{\circ} \mathrm{C}$. A contagem foi realizada aos cinco dias após a semeadura, computando-se a porcentagem de plântulas normais, segundo os critérios estabelecidos nas Regras para Análise de Sementes (Brasil, 1992).

Para o estudo do teste de tetrazólio foram utilizadas quatro subamostras de 50 sementes por tratamento, avaliando-se diferentes combinações período/temperatura/ formas de hidratação, bem como período/temperatura/ preparo/concentração da solução de cloreto de tetrazólio, cujos procedimentos são discriminados a seguir:

a) Hidratação - Foram testadas duas formas de hidratação:

a.1) sementes acondicionadas em papel toalha umedecido com quantidade de água equivalente a 2,5 vezes a massa do papel por $18 \mathrm{~h}$ a $20{ }^{\circ} \mathrm{C}$ (Brasil, 1992; ISTA, 2003);

a.2) imersão direta em $30 \mathrm{~mL}$ de água, colocadas em copo de béquer (capacidade de $100 \mathrm{~mL}$ ) por $18 \mathrm{~h}$ a $20{ }^{\circ} \mathrm{C}$ (Brasil, 1992; ISTA, 2003) .

Juntamente com o procedimento de hidratação, foi determinado o grau de umidade das sementes após o précondicionamento. Para a primeira hidratação estudada (item a.1), a determinação foi realizada através do método de estufa a $105 \pm 3{ }^{\circ} \mathrm{C}$, por $24 \mathrm{~h}$ (Brasil, 1992). Na segunda hidratação (item a.2), o grau de umidade foi obtido a partir da seguinte fórmula:

Porcentagem de água $=\{($ massa final - massa inicial $) /$ massa inicial $\}$ x 100

b) Preparo - Com o término da hidratação, as sementes de cada lote foram bisseccionadas longitudinalmente através do embrião e depois submetidas aos seguintes preparos:

b.1) descarte de uma das metades e imersão da outra em $5 \mathrm{~mL}$ de solução de cloreto de 2, 3, 5 trifenil tetrazólio, em copo de béquer (capacidade de $100 \mathrm{~mL}$ ), colocadas para colorir a $30^{\circ} \mathrm{C}$ (Brasil, 1992; ISTA, 2003);

b.2) colocação das duas metades sobre uma folha de papel filtro umedecido com solução de tetrazólio equivalente a 2,5 vezes a massa do papel, e colocadas para colorir a $40{ }^{\circ} \mathrm{C}$.

c) Coloração - Após o preparo descrito anteriormente, as sementes foram colocadas para coloração em ambiente escuro por $2 \mathrm{~h}$, com concentrações da solução de tetrazólio a $0,1 \%, 0,5 \%$ e $1,0 \%$. Decorrido o período de coloração, no primeiro preparo (item b.1) as sementes foram retiradas da câmara, lavadas em água corrente e mantidas submersas em água sob refrigeração $\left(5^{\circ} \mathrm{C}-10{ }^{\circ} \mathrm{C}\right)$, até o momento da avaliação; para o segundo preparo (item b.2), as sementes foram mantidas em refrigeração $\left(5^{\circ} \mathrm{C}-10^{\circ} \mathrm{C}\right)$ sobre papel filtro.

Para avaliação da viabilidade da semente foram observadas suas estruturas com o auxílio de microscópio estereoscópico, seguindo recomendações de Grabe (1976) para cereais de semente pequena. Nas sementes de Poaceae, como as de aveia branca, as áreas vitais para análise são: plúmula, coleóptilo, região central do escutelo, radícula e a região das raízes seminais (Dias e Barros, 1999). As sementes foram classificadas em viáveis e não viáveis de acordo com a coloração apresentada no eixo embrionário, computando-se a porcentagem de sementes viáveis.

$\mathrm{O}$ delineamento experimental foi inteiramente casualizado, com quatro repetições, combinando as formas de hidratação e de coloração estudadas. A comparação de médias foi realizada pelo teste de Tukey, a 5\% de probabilidade. Os dados de grau de umidade não foram analisados estatisticamente.

\section{RESULTADOS E DISCUSSÃO}

Com a avaliação inicial da qualidade fisiológica das sementes, realizada pelo teste de germinação (Tabela 1), os lotes foram separados em alta (1, 4 e 5), média (2) e baixa (3) viabilidade.

TABELA 1. Médias de germinação e do grau de umidade das sementes de cinco lotes de aveia branca (lotes 1 e 2 da cultivar Louise e lotes 3, 4 e 5 da cultivar IAC-7).

\begin{tabular}{ccc}
\hline Lotes & Germinação $(\%)$ & Grau de umidade $(\%)$ \\
\hline 1 & $94 \mathrm{a}$ & 12,9 \\
2 & $88 \mathrm{~b}$ & 12,8 \\
3 & $73 \mathrm{c}$ & 12,7 \\
4 & $98 \mathrm{a}$ & 13,0 \\
5 & $96 \mathrm{a}$ & 12,6 \\
\hline
\end{tabular}

C.V. (\%)

2,48

Médias seguidas pela mesma letra na coluna não diferem entre si pelo teste de Tukey, a $5 \%$ de probabilidade.

Quanto ao grau de umidade inicial das sementes, os cinco lotes estudados apresentaram-se semelhantes, variando de 12,6 a 13,0\% (Tabela 1), sendo isso muito importante para a execução dos testes, uma vez que a uniformidade do grau de umidade das sementes é fundamental para a padronização das avaliações e obtenções de resultados consistentes (Marcos Filho, 1999). 
$\mathrm{Na}$ Tabela 2, encontram-se os resultados do teste de tetrazólio para o procedimento realizado com hidratação entre papel e coloração sobre papel. Observase que na concentração a $1,0 \%$ os lotes foram separados semelhantemente ao teste de germinação (Tabela 1), classificando os lotes 1,4 e 5 como de qualidade superior, o lote 2 como intermediário e o lote 3 como o de pior desempenho. A ISTA (2003) recomendou para a aveia branca esta metodologia, porém com coloração por imersão. Os resultados obtidos na presente pesquisa revelaram a possibilidade de coloração das sementes sobre papel umedecido com solução de tetrazólio.

TABELA 2. Valores médios obtidos no teste de tetrazólio em sementes de cinco lotes de aveia branca (lotes 1 e 2 da cultivar Louise e lotes 3, 4 e 5 da cultivar IAC-7), conduzido com hidratação entre papel e coloração sobre papel $\left(40^{\circ} \mathrm{C}\right)$, utilizando-se diferentes concentrações do sal.

\begin{tabular}{cccc}
\hline \multirow{2}{*}{ Lotes } & \multicolumn{5}{c}{ Hidratação entre papel - Coloração sobre papel } \\
\cline { 2 - 4 } & 0,1 & Concentrações do sal de tetrazólio (\%) & 1,0 \\
\cline { 2 - 4 } & $76 \mathrm{bc}$ & 0,5 & $94 \mathrm{a}$ \\
2 & $75 \mathrm{c}$ & $94 \mathrm{ab}$ & $89 \mathrm{~b}$ \\
3 & $76 \mathrm{bc}$ & $80 \mathrm{bc}$ & $77 \quad \mathrm{c}$ \\
4 & $91 \mathrm{ab}$ & $98 \mathrm{a}$ & $95 \mathrm{a}$ \\
5 & $93 \mathrm{a}$ & $96 \mathrm{a}$ & $96 \mathrm{a}$ \\
\hline C.V. $(\%)$ & 8,84 & 3,87 & 2,36 \\
\hline
\end{tabular}

Médias seguidas pela mesma letra na coluna não diferem entre si pelo teste de Tukey, a $5 \%$ de probabilidade.

O procedimento de preparo, com a colocação das duas metades da semente para coloração sobre papel, facilita a avaliação do teste, pois quando se tem apenas uma das metades pode haver dúvida quanto à coloração dos tecidos da semente, devido à dificuldade de cortar exatamente ao meio o pequeno embrião. Esse fato foi observado também por Dias e Alves para sementes de braquiária (2008a) e de capim colonião (2008b).

Empregando-se a metodologia de hidratação entre papel, mas com coloração por imersão na solução de tetrazólio (Tabela 3), pode-se verificar que nas três concentrações testadas não foi possível separar o lote 2 como de desempenho intermediário, classificando-o como de alta qualidade juntamente com os lotes 1, 4 e 5, diferentemente do obtido no teste de germinação (Tabela 1). Esse procedimento de coloração por imersão, embora seja recomendado pela ISTA (2003) e pelas Regras para Análise de Sementes (Brasil, 1992) apresenta o inconveniente de dificultar a avaliação, uma vez que intensifica a cor nos tecidos da semente e provoca maior hidratação da mesma, prejudicando a identificação da sua viabilidade.

TABELA 3. Valores médios obtidos no teste de tetrazólio em sementes de cinco lotes de aveia branca (lotes 1 e 2 da cultivar Louise e lotes 3, 4 e 5 da cultivar IAC-7), conduzido com hidratação entre papel e coloração com imersão $\left(30^{\circ} \mathrm{C}\right)$, utilizando-se diferentes concentrações do sal.

\begin{tabular}{clcc}
\hline & \multicolumn{3}{c}{ Hidratação entre papel - Coloração com imersão } \\
\cline { 2 - 4 } Lotes & \multicolumn{3}{c}{ Concentrações do sal de tetrazólio (\%) } \\
\cline { 2 - 4 } & $93 \mathrm{a}$ & 0,5 & 1,0 \\
\hline 1 & $93 \mathrm{a}$ & $96 \mathrm{a}$ & $96 \mathrm{a}$ \\
2 & $81 \mathrm{~b}$ & $92 \mathrm{a}$ & $90 \mathrm{a}$ \\
3 & $96 \mathrm{a}$ & $78 \mathrm{~b}$ & $76 \mathrm{~b}$ \\
4 & $97 \mathrm{a}$ & $94 \mathrm{a}$ & $95 \mathrm{a}$ \\
5 & 4,58 & $93 \mathrm{a}$ & $92 \mathrm{a}$ \\
\hline C.V. $(\%)$ & 5,58 & 3,75 \\
\hline
\end{tabular}

Médias seguidas pela mesma letra na coluna não diferem entre si pelo teste de Tukey, a $5 \%$ de probabilidade. 
Com a metodologia de hidratação por imersão e coloração sobre papel (Tabela 4), pode-se observar novamente que na concentração de $0,1 \%$ o lote intermediário (2) não foi separado dos de melhor desempenho (1, 4 e 5) e, nas demais concentrações estudadas (0,5 e 1,0\%), a metodologia não foi eficiente para a classificação dos lotes quanto à viabilidade. Provavelmente, a razão para esse resultado esteja associada à combinação inadequada de tipo/período de hidratação, ocasionando uma hidratação mais intensa da semente, que atingiu grau de umidade entre 74,1 e $90,1 \%$ (Tabela 6 ).

O pré-condicionamento das sementes tem como finalidade ativar o metabolismo enzimático, facilitar o preparo e o desenvolvimento da coloração durante o contato com a solução de tetrazólio (Marcos Filho, 2005). Normalmente, os resultados dos testes estão associados ao grau de umidade atingido pela semente durante o précondicionamento, ocasionando ou não uma ativação enzimática adequada.

Na Tabela 5, estão apresentados os dados obtidos com a metodologia de hidratação com imersão em água e coloração por imersão na solução de tetrazólio. Pode-se verificar que, mais uma vez, o lote intermediário (2) não foi separado quanto a viabilidade dos lotes de alta qualidade (1, 4 e 5).

A representação dos tecidos das sementes de aveia branca após a coloração sobre papel pode ser visualizada na Figura 1, onde estão apresentadas sementes viáveis e não viáveis. Desta forma, a semente viável (Figura 1A) apresentou coloração vermelho carmim claro nas áreas vitais e a não viável (Figura 1B) apresentou os tecidos com coloração branca, uma vez que não ocorreu a redução do sal de tetrazólio.

TABELA 4. Valores médios obtidos no teste de tetrazólio em sementes de cinco lotes de aveia branca (lotes 1 e 2 da cultivar Louise e lotes 3, 4 e 5 da cultivar IAC-7), conduzido com hidratação por imersão em água e coloração sobre papel $\left(40^{\circ} \mathrm{C}\right)$, utilizando-se diferentes concentrações do sal.

\begin{tabular}{cccc}
\hline & \multicolumn{3}{c}{ Hidratação por imersão - Coloração sobre papel } \\
\cline { 2 - 4 } Lotes & \multicolumn{3}{c}{ Concentrações do sal de tetrazólio (\%) } \\
\cline { 2 - 4 } & 0,1 & 0,5 & 1,0 \\
\hline 1 & $94 \mathrm{a}$ & $96 \mathrm{a}$ & $94 \mathrm{a}$ \\
2 & $92 \mathrm{a}$ & $92 \mathrm{ab}$ & $87 \mathrm{a}$ \\
3 & $82 \mathrm{~b}$ & $82 \mathrm{~b}$ & $87 \mathrm{a}$ \\
4 & $96 \mathrm{a}$ & $96 \mathrm{a}$ & $93 \mathrm{a}$ \\
5 & $91 \mathrm{a}$ & $93 \mathrm{ab}$ & $92 \mathrm{a}$ \\
\hline C.V. $(\%)$ & 3,49 & 5,54 & 5,95 \\
\hline
\end{tabular}

Médias seguidas pela mesma letra na coluna não diferem entre si pelo teste de Tukey, a 5\% de probabilidade.

TABELA 5. Valores médios obtidos no teste de tetrazólio em sementes de cinco lotes de aveia branca (lotes 1 e 2 da cultivar Louise e lotes 3, 4 e 5 da cultivar IAC-7), conduzido com hidratação por imersão em água e coloração com imersão $\left(30^{\circ} \mathrm{C}\right)$, utilizando-se diferentes concentrações do sal.

\begin{tabular}{cccc}
\hline & \multicolumn{3}{c}{ Hidratação por imersão - Coloração com imersão } \\
\cline { 2 - 4 } Lotes & \multicolumn{3}{c}{ Concentrações do sal de tetrazólio (\%) } \\
\cline { 2 - 4 } & 0,1 & 0,5 & $92 \mathrm{a}$ \\
\hline 1 & $95 \mathrm{a}$ & $96 \mathrm{a}$ & $93 \mathrm{a}$ \\
3 & $95 \mathrm{a}$ & $93 \mathrm{ab}$ & $83 \mathrm{~b}$ \\
4 & $84 \mathrm{~b}$ & $87 \mathrm{~b}$ & $90 \mathrm{ab}$ \\
5 & $95 \mathrm{a}$ & $93 \mathrm{ab}$ & $91 \mathrm{ab}$ \\
\hline C.V. $(\%)$ & $95 \mathrm{a}$ & $90 \mathrm{ab}$ & 4,45 \\
\hline
\end{tabular}

Médias seguidas pela mesma letra na coluna não diferem entre si pelo teste de Tukey, a 5\% de probabilidade. 
TABELA 6. Grau de umidade de sementes de cinco lotes de aveia branca (lotes 1 e 2 da cultivar Louise e lotes 3, 4 e 5 da cultivar IAC-7), após período de hidratação de $\mathbf{1 8}$ horas, a $20{ }^{\circ} \mathrm{C}$, por imersão e entre papel.

\begin{tabular}{|c|c|c|}
\hline \multirow{2}{*}{ Lotes } & \multicolumn{2}{|c|}{ Grau de umidade (\%) após hidratação } \\
\hline & Por imersão & Entre papel \\
\hline 1 & 88,4 & 28,7 \\
\hline 2 & 90,1 & 29,1 \\
\hline 3 & 86,4 & 27,8 \\
\hline 4 & 74,1 & 27,4 \\
\hline 5 & 74,1 & 27,9 \\
\hline
\end{tabular}

A

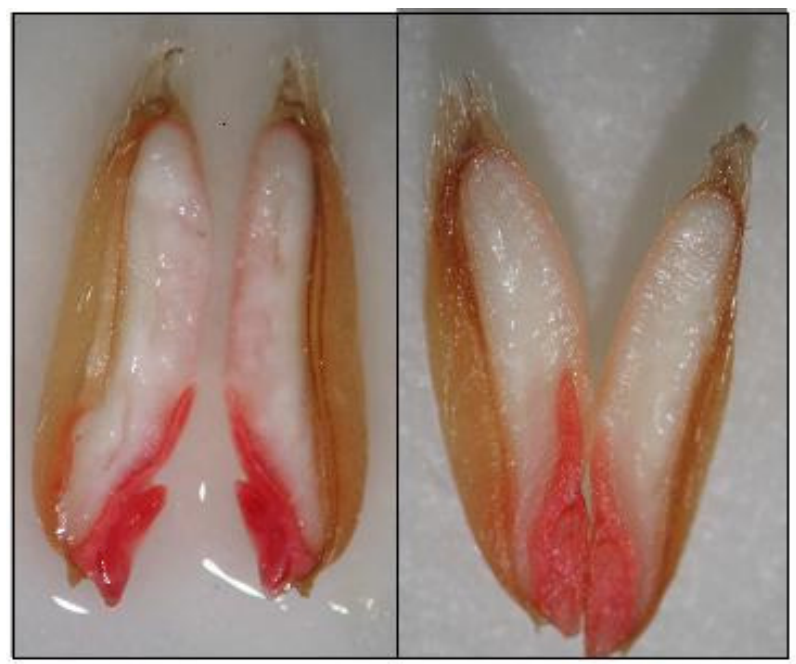

B

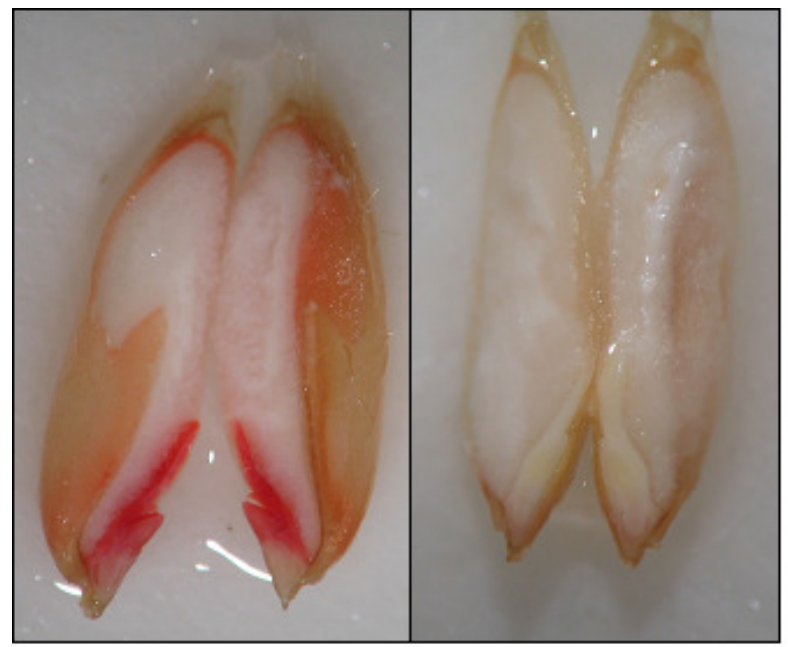

FIGURA 1. Sementes viáveis (A) e não viáveis (B) de aveia branca pelo teste de tetrazólio

\section{CONCLUSÕES}

O teste de tetrazólio é promissor para a avaliação rápida da viabilidade de sementes de aveia branca, por meio da seguinte metodologia: hidratação entre papel por 18 horas a $20{ }^{\circ} \mathrm{C}$, com coloração sobre papel por duas horas a $40{ }^{\circ} \mathrm{C}$ e concentração de solução de tetrazólio a 1,0\%.

\section{REFERÊNCIAS}

ALMEIDA, J.L. Produção e utilização recente da aveia no Brasil. In: REUNIÃO DA COMISSÃO BRASILEIRA DE AVEIA, 18., Londrina, 14/16 abr.1998. Palestras... Londrina: IAPAR, 1998. p.5-15.

BORSATO, A.V.; BARROS, A.S.R.; AHRENS, D.C.; DIAS, M.C.L.L. Avaliação de testes de vigor para sementes de aveia branca. Revista Brasileira de Sementes, v.22, n.1, p.163-168, 2000.

BRASIL. Ministério da Agricultura e Reforma Agrária. Secretaria Nacional de Defesa Agropecuária. Departamento Nacional de Defesa Vegetal. Coordenação de Laboratório Vegetal. Regras para análise de sementes. Brasília, DF, 1992. 365p.

CALEGARI, A.; ASSMANN, A.L.; SANGUININI, J.N. Influência do sistema de cultivo e da adubação verde de inverno na agregação do solo. In: CONGRESSO BRASILEIRO DE PLANTIO DIRETO PARA UMA AGRICUltURA SUSTENTÁVEL, 1., Ponta Grossa, 18/22. Anais... Londrina: IAPAR, 1996, p.95-97.

COMISSÃO BRASILEIRA DE PESQUISA DE AVEIA CBPA. Recomendações técnicas para a cultura da aveia. IAPAR: Londrina, 1999. 60p.

DELATORRE, C.A.; SOUZA, P.A.E. Dormência de genótipos brasileiros de aveia. Revista Brasileira de Fisiologia Vegetal, v.10, n.2, p.149-152, 1998.

DIAS, M.C.L.L.; ALVES, S.J. Avaliação da viabilidade de sementes de Brachiaria brizantha (Hochst. Ex A. Rich) Stapf pelo teste de tetrazólio. Revista Brasileira de Sementes, v.30, n.3, p.145-151, 2008a.

DIAS, M.C.L.L.; ALVES, S.J. Avaliação da viabilidade de sementes de Panicum maximum Jacq pelo teste de tetrazólio. Revista Brasileira de Sementes, v.30, n.3, p.152-158, 2008b. 
DIAS, M.C.L.L.; BARROS, A.S.R. Metodologia do teste de tetrazólio em sementes de milho. In: KRZYZANOWSKI, F.C., VIEIRA, R.D., FRANÇA NETO, J.B. (Ed.). Vigor de sementes: conceitos e testes. Londrina: ABRATES, 1999. cap.8.4, p.1-10.

GARCIA, D.C.; MENEZES, N.L. Teste de envelhecimento precoce para sementes de azevém, aveia preta e milheto.

Ciência Rural, v.29, n.2, p.233-237, 1999.

GRABE, D.F. Manual do teste de tetrazólio em sementes. Brasília, DF: AGIPLAN, 1976. 85p.

INTERNATIONAL SEED TESTING ASSOCIATION ISTA. In: ISTA Working Sheets on Tetrazolium Testing. Bassersdorf: ISTA, v.1, 2003. 171p.

INTERNATIONAL SEED TESTING ASSOCIATION ISTA. International Rules for Seed Testing. In: Chapter 6: Biochemical Test for Viability, The Topographica
Tetrazolium Test. Bassesrdorf: ISTA, 2007.46p.

MARCOS FILHO, J. Teste de envelhecimento acelerado. In: KRZYZANOWSKI, F.C., VIEIRA, R.D., FRANÇA NETO, J.B. (Ed.). Vigor de sementes: conceitos e testes. Londrina: ABRATES, 1999. cap.3, p.1-24.

MARCOS FILHO, J. Fisiologia de sementes de plantas cultivadas. Piracicaba: FEALQ, 2005. 495p.

OLIVEIRA, L.M.; CARVALHO, M.L.M.; DAVIDE, A.C. Teste de tetrazólio para avaliação da qualidade de sementes de Peltophorum dubium (Sprengel) Taubert - Leguminosae Caesalpinioideae. Cerne, v.11, n.2, p.159-166, 2005.

VIEIRA, M.G.G.C.; VON PINHO, E.V.R. Metodologia do teste de tetrazólio em sementes de algodão. In: KRZYZANOWSKI, F.C., VIEIRA, R.D., FRANÇA NETO, J.B. (Ed.). Vigor de sementes: conceitos e testes. Londrina: ABRATES, 1999. cap. 8.1, p.1-13. 